Vantage: Journal of Thematic Analysis

ISSN: 2582-7391

A Multidisciplinary Publication of Centre for Research,

Maitreyi College, University of Delhi

October 2021, Volume 2, Issue 2

Report

\title{
Equinox 2021: The Annual International Conference
}

\author{
Khushi Talwar* \\ Department of Sociology, Maitreyi College, University of Delhi \\ *Correspondence: khushitalwar3108@gmail.com
}

The Centre for Research, Maitreyi College, University of Delhi, organized a three-day Annual International Conference, Equinox 2021, under the aegis of Vantage: Journal of Thematic Analysis, from $12^{\text {th }}$ to $14^{\text {th }}$ August, 2021. Prof. Haritma Chopra, Officiating Principal, Maitreyi College was the coordinator of the conference and Dr. Gopi Devdutt Tripathy, Department of Sociology, Dr. Brototi Roy, and Dr. Meena Yadav, Department of Zoology, Maitreyi College were the convenors. The theme for the conference was Sustainable Agriculture: Negotiating Tradition and Modernity.

The terms 'tradition' and 'modernity' are used to describe processes of ideological and technological change in society over time. They address two different and opposed ways of assessing the world, of people and things, and of the relationship between man and nature. The focus of traditional agricultural system is on the fulfilment of natural needs. It is labour-intensive, involves the use of traditional tools and natural resources for irrigation and the practices are grounded in traditional knowledge and beliefs. The focus of the modern agriculture, in contrast, is on the fulfilment of a profit motive, wherein technological advancements enable quicker and greater production in lesser time. It is based on the use of contemporary scientific methods and is grounded in the epistemology of the physical and natural sciences. The conference aimed to initiate a dialogue around these systems of agriculture among students, scientists, and policymakers in the context of the sustainability debate. There were more than 200 participants in the conference, from not only several states of India including states of Northeast and Southern India but also from other countries like UK, Japan, Turkey and 
Sri Lanka. The participants were from diverse disciplines such as sciences, social sciences, education, economics, commerce, civil engineering, philosophy, computers, horticulture, agronomy, Sanskrit, Food technology, languages etc.

Session I was inaugurated by the Coordinator of Equinox 2021, Professor Haritma Chopra, followed by an address by Shri. Santosh Kumar Taneja, Chairperson, Governing Body, Maitreyi College. Professor S.P.S. Beniwal, Founder Member and Chairperson of Asian Agri History Foundation was the Chief Guest at the session and delivered the key note address on "The Potential and Relevance of Vrikshaayurveda in Sustainable Agriculture including Organic Cultivation in South Asia". Vrikshaayurveda practices have tremendous potential for eco-friendly sustainable agriculture as evidenced by the encouraging results obtained by the Asian Agri-History Foundation. The Inaugural Session ended with the release of the Book of Abstracts comprising of the abstracts of all the papers presented at the conference.

In Session II, Dr. Chandish Ballal, Former Director, ICAR-NBAIR, spoke on the topic, "Biological Control for Sustainable Plant Protection." She asserted that it is important to consider biological control as the most promising technology for sustainable protection. Dr. Shaikh Tanveer Hossain, Ambassador, IFOAM Organic International, and ALGOA, Tokyo, Japan talked about "Innovations in Asia: Making Organic Agriculture More Sustainable." He focussed on how to make organic agriculture transparent and protect consumers from fraudulent claims, particularly in resourceconstraint economies. He also shared updated information on innovative examples of organic agriculture in Asia, along with opportunities for collaboration and networking in the region and beyond.

In Session III, Mr. Satyajit Hange, Co-Founding Farmer, Two Brothers Organic Farm spoke on "My Exciting Journey: Banker to Organic Farmer with Customers across the Globe." Mr Hange spoke about his journey alongside his brother, from being bankers to becoming farmers, and the challenges they faced along the way.

Session IV of first day of the conference included platform presentations by the faculty members on a variety of topics, ranging from Tea Tourism and Agricultural Waste 
Management to Folklore Around Agricultural Practices, Importance of Innovative Technology and Effects of Vermicompost, and more.

The theme for the first session of the second day of the conference was: Social Issues Related to Sustainable Agriculture. Speaking on "The Significance of Plant Intelligence for Sound Cultivation", Professor Savyasaachi, Department of Sociology, Jamia Milia Islamia, suggested that an understanding of non-anthropocentric intelligence could be the basis for the sound cultivation of food crops contributing to building communications between humans and "non-human" nature. Professor A.R. Vasavi, Independent Scholar and Secretary Punarchith Collective, Karnataka talked about "Agricultures and the Plurality of India". She asserted that the erosion of India's "agricultures" lies in "the erosion of India's plural cultures itself". She argued that it is important to retrieve these "agri-cultures" in order to "revitalize our cultural pluralism and rebuild societies on the basis of democracy, decentralization, diversity and dignity."

The theme for the next session was: Innovative Technologies in Agriculture. Professor G.K. Garg, G.B. Pant University of Agriculture and Technology, Pantnagar gave a talk on "Bt Cotton Adoption in India: Blessing or Curse to Farmers." He gave an insight into the social impact of the introduction of transgenics in agriculture. He mentioned that cotton cultivation has undergone a drastic reduction, in area, since 2002. From being an exporter of cotton earlier, India has now become a net importer.

Session III of the day featured platform presentations by students in parallel sessions on themes ranging from food safety and biotechnology and organic/natural farming and biocontrol to sustainable agriculture, development and management, and social issues related to agriculture.

The final day of the conference began with a session on the theme, Agrarian Transformation and Economics of Post-Harvest Management Practices. A talk on "Jhum or not to Jhum: Highland Agrarian Transformation in Northeast India" by Dr Debojyoti Das, Lecturer, School of Global Studies, University of Sussex, UK engaged with the theme of rural labour relations as elements of larger political and economic systems. Dr Nitu Goswami, Consultant, IIPA, New Delhi; Visiting Faculty, University of Fraser Valley, British Columbia, Canada presented a talk on "The 
Economics of Post-Harvest Management Practices amid Dwindling Agriculture in India." Dr Goswami asserted that it is necessary to set the right direction for investments in infrastructure such as mandis, cold chains, storage, etc. to reap real benefits for farmers.

Session II, the Valedictory Session, comprised addresses by Mr. Sumit Singh, Member Governing Body, Maitreyi College and the Guest of Honour, Professor Ashok K. Prasad, Dean, Faculty of Sciences and Head, Department of Chemistry, University of Delhi.

In its entirety, the conference explored a paradigm shift that is the need of the hour, where technological developments are used effectively while keeping in mind the ecological balance, using traditional farming techniques. Equinox 2021 brought in awareness about sustainable agricultural practices and inspired people to engage more proactively with it, to ensure a more secure future.

How to cite this article: Talwar, K. (2021). Equinox 2021: The Annual International Conference. Vantage: Journal of Thematic Analysis, 2(2):

DOI: https://doi.org/10.52253/vjta.2021.v02i02.08

(C) The Author(s) 2021.

This work is licensed under a Creative Commons Attribution 4.0 International License which permits its use, distribution and reproduction in any medium, provided the original work is cited 